\title{
Contemporary Global Issue of Rising Water Scarcity for Agriculture: The Quest for Effective and Feasible Soil Moisture and Free-Water Surface Conservation Strategies
}

\author{
Sunday E. Obalum ${ }^{1 *}$, Gloria I. Ezenne ${ }^{2}$, Yoshinori Watanabe ${ }^{3}$ Toshiyuki Wakatsuki $^{3}$ \\ ${ }^{1}$ Department of Soil Science, University of Nigeria, Nsukka, Nigeria \\ ${ }^{2}$ Department of Agricultural and Bioresources Engineering, University of Nigeria, Nsukka, Nigeria \\ ${ }^{3}$ Ecotechnology Laboratory, School of Agriculture, Kinki University, Nara, Japan \\ *E-mail: ijewelle@yahoo.com
}

Received December 15, 2010; revised January 15, 2011; accepted February 19, 2011

\begin{abstract}
There is the need to take seriously the task of conserving soil moisture in agricultural fields and free-water surfaces in reservoirs, especially in recent years of climate change. Many strategies exist for achieving this task and improving the productivity of arable soils. These strategies traditionally come under biological and physical or mechanical measures. Some other relatively new techniques operate neither on physical nor on biological principle. All these measures which operate on different principles frequently overlap. The principles involved, together with the prospects and constraints of the key techniques of conserving soil moisture found in the literature, are reviewed in this paper. Among other considerations, the effectiveness and/or practicability of any one of the techniques depend upon soil type, topography, climate, scale of production, level of technology, and socio-economic status. Such agronomic practices as conservation tillage and live vegetation mulch that maintain infiltration rates often appear to be more beneficial in the long run than engineering structures, especially those that lead to blocking of waterways on the soil surface. However, this review reveals that none of the soil moisture conservation strategies could be credited as universally applicable. Consequently, an integrated approach to soil water management and conservation, where feasible, is considered more appropriate. This is because the different principles involved in the techniques identified to be compatible would readily complement and strengthen one another. Such a multi-mechanistic approach is expected to result in improved efficacy in conserving water resources in soils and open reservoirs.
\end{abstract}

Keywords: Effective Rainfall, Evapotranspiration Rate, Deep Percolation, Losses to Seepage, Integrated Soil Moisture Conservation Strategies

\section{Introduction}

Soil moisture is, perhaps, the single most critical factor in crop production. Its status determines greatly the proportion of the year during which the soil is cultivated with the purpose of starting a new crop life cycle. This constraint is encountered not only in arid and semi-arid regions but also in sub-humid and humid regions where, according to FAO [1], the rains are partitioned into "productive" and "unproductive" water flows. In these regions where there is a theoretical need to dispose of excess water, Aina [2] argued that dry periods with water deficit frequently occur and cases of positive responses to moisture conservation techniques are common. Aina [2] noted that in rainfed systems, the constraint is not only the erratic rainfall distribution, but also the amount of rainfall that could be retained in the active root zone. This stored water, which is affected less in drier regions and more in wetter regions by deep percolation, is needed to survive drought stress period. Deep percolation is in turn affected by soil texture, among other factors. It seems that the epicenter of this agronomic problem is low soil water storage, and therefore should be an issue of major concern. Even in wet regions where the crop water requirements might be sufficiently met by rain input, the quantity of water stored in the root zone after cessation of the rains is always too small to permit all-year-round crop production.

Highlighting the importance of water in agriculture, 
Ahaneku [3] noted that crops can be grown without fertilizers and even without soil, but they cannot survive without water. Besides the constraints to crop production, unfavourable soil moisture status hampers the capacity of soils to carry out their environmental regulatory functions. In recent years, major agricultural regions of the world experience declining water resources due mainly to climate change. In contrast, agricultural water consumption is steadily on the rise and may hit $3200 \mathrm{~km}^{3}$ per year by 2025 , representing about $26 \%$ of the value in 1995 [4]. Major avenues of soil moisture loss include evaporation and deep percolation. These avenues are mainly influenced by conductivity of the soil, albedo of ground surface, and soil texture. There is the need to appreciably minimize unproductive losses of moisture at the soil surface (by encouraging infiltration and reducing runoff and evaporation) and in the crop root zone (by increasing the ratio between root water uptake and deep percolation) in favour of productive transpiration in order to attain an increased water productivity [1]. This could be achieved by a combination of adequate soil and crop management strategies for that encourage infiltration and maintain conductivity at favorable levels. Soil water management strategies should also incorporate techniques aimed at "harvesting" and reusing runoff for protective irrigation [1].

Many agronomic practices or techniques exist which are used for conserving soil moisture and/or ensuring maximum infiltration of runoff and minimum evaporation from soil or free-water surface. These practices operate on different principles. As a result, their individual effectiveness in this onerous task differs widely. Though each of these strategies is designed primarily for moisture conservation, a good number of them offer some other agronomic benefits. Others have some side effects either on the soil or on the crops growing on it, or are simply impracticable. All these concerns, and possibly more, ought to be put into consideration before selecting any strategy. In a critical analysis of the developments in harvesting and conservation of water resources across countries of the world, Coopey et al. [5] highlighted the importance of compatibility of a chosen technique with nature. The suitability of any practice in any location must therefore be ascertained before adoption. To do this with minimal error, the prospects and constraints of available strategies need to be explored. Although soil and water conservation techniques could have significant impacts on reducing production risk, no single technique is universally appropriate given the differences in agroecology and other factors [6]. There is therefore the need for information on the various soil moisture conservation strategies, the principles upon which they operate, their relative effectiveness, as well as their potential benefits and drawbacks. This paper aims at providing such information, which is expected to guide stakeholders in making decisions about the techniques suitable for their scenario.

\section{Principles of Soil Moisture Conservation}

Most management strategies aimed at conserving soil moisture work on the principle of either modifying the soil condition to enhance water retention and/or barricading avenues of soil water depletion. For instance, the management practice of especially maintaining optimum levels of organic matter in the topsoil could have dual effects. Such a condition, by reducing the soil bulk density and promoting favourable aggregation, encourages infiltration of rainwater and runoff especially when impounded in some depressions. On the other hand, organic matter imparts a darkish colouration to the soil, thereby minimizing evaporative flux. This is because energy supply to the site of evaporation could be controlled by modifying soil albedo through colour [7]. Soil colour affects reflectance which in turn affects the rate of evaporative moisture losses. Control of "unavoidable" deep percolation below the root zone and supra-optimal evaporation rate caused by high insolation and high wind intensity and speed is based on the "barrier" principle.

\section{Major Soil Moisture and Free-Water Surface Conservation Techniques}

Soil moisture conservation techniques are traditionally described under two convenient headings namely biological measures and physical or mechanical measures [8]. Today, some chemicals are even used in conserving soil moisture and for protecting water in reservoirs. For instance, the maintenance of live vegetation as mulch is a sound agronomic practice for improving soil and water conservation [9], but this could hardly be classified as a biological or as a physical technique.

\subsection{Biological Techniques of Soil Moisture Conservation}

These techniques employ live vegetation especially growing crops in the task of conserving soil moisture. Management of soil and water in agriculture obviously includes cropping techniques [1]. The effectiveness of these techniques could be enhanced through intercropping. This is because intercropping often results in decreased soil erosion and increased conservation of soil moisture because ground cover is greater than with monocropping [10]. Ideally, the land area cover to be provided by intercropping should be about $90 \%$ to ensure optimum effects. Such a sufficient crop density is required to shield the soil surface from the direct impact of insolation and to create a rough surface that would physically impede runoff to 
enhance infiltration. Since reduction in wind speed lessens evaporation and transpiration [11], use of windbreaks in agricultural fields is another barrier-oriented strategy. In general, biological technique, by ensuring high infiltration into the soil, is one of the best means of minimizing runoff [2]. A number of crops have proved useful in biological measures of soil moisture conservation. Groundnut, for example, is an important cash crop with a high potential for soil and water conservation [9]. Other planted cover crops such as Mucuna pruriens utilis, $\mathrm{Pu}$ eraria phaseolides, Centrosema pubescens, Setaria spp., Stylosanthes spp., and Glycine spp. all provide in-situ mulch services [2]. Notably, all cover crops actually functions as live 'mulch'. It is therefore not uncommon in the literature to see this biological technique referred to as biological mulch [12]. The function of live vegetation as mulch is a typical example of the overlap between biological and physical techniques. So also is the use of windbreaks especially in agroforestry to lessen the effect of wind speed on evaporation. Such cases of overlap could be regarded as biophysical techniques.

Control of weeds and phreatophytes could also be regarded as a biological measure of soil moisture conservation. According Schwab et al. [13], phreatophytes include plants that habitually obtain their water supply from the zone of saturation or from overlying capillary fringe, such as tamarisk, cottonwood, willow, and mesquite. The shallower the depth to the groundwater table, the higher the consumptive use of water by these weeds. Control of phreatophytes thus offers a great potential for water conservation [13]. This could be most effectively achieved through removal. On sloping lands, creation of rough surface to slow down runoff would be the first objective. One of the most effective biological considerations is the practice of contour strip cropping. It involves growing two or more crops on sloping land in alternating contoured strips, normally aligned perpendicular to the direction of surface water flow [14].

\subsection{Physical or Mechanical Measures of Soil Moisture Conservation}

These measures are a totality of all techniques that operate on the principle of modifying the physical condition of the soil and/or constituting a physical barrier/impedance to minimize any of runoff, evaporation, seepage, and deep percolation. Included in this category are both "simple" approaches that do not need any special designs and/or construction and "sophiscated" approaches that involve special designs with construction and earthworks or other engineering structures. A combination of these two approaches is also possible. The simple ones include mainly tillage, mulch, and manuring practices. In conserving soil moisture, tillage and manuring employ modification in soil physical condition whereas mulch employs formation of a physical barrier. Where necessary, any two of the three or the whole three practices could be combined to enhance effectiveness. On the other hand, sophiscated mechanical conservation works do little or nothing to prevent the evaporative impact of insolation. They are only designed to slow down partially or entirely the movement of runoff so that the infiltration rate is increased. According to Sanders [8], they achieve this either by reducing the length of slope (e.g. contour banks) or by changing the degree of slope (e.g. bench terraces). Reduction in slope is important in soil moisture conservation because slope affects infiltration [13].

\subsubsection{Tillage, Mulch, and Manuring Practices}

The presence of large clods in the field helps to improve the amount of infiltration since the soil presents relatively large surface area while the excess water is temporarily held in the spaces between the clods as it infiltrates into the soil [10]. The choice of an appropriate type of tillage that would leave large clods on the soil surface for optimum infiltration of water depends on texture and antecedent moisture content of the soil. Various types of tillage are used in conservation of soil moisture and they include:

1) Conservation tillage: Major goals of conservation tillage are improved maintenance of surface residue for erosion control and efficient water conservation in different agro-ecological regions [16]. According to this author, the Conservation Technology Information Centre (CTIC) in West Lafayette of Indiana in USA defines conservation tillage as any tillage or planting system in which at least $30 \%$ of the soil surface is covered by plant residue after planting to reduce erosion by water. Where soil erosion by wind is the primary concern, at least 1120 $\mathrm{kg} \mathrm{ha}^{-1}$ flat small grain residue should be maintained on the surface during the critical wind erosion period. This definition excludes conventional tillage operations that invert the soil and bury crop residues. Generally, moisture conservation benefits of conservation tillage usually result from improvement of soil structure in such a way that favours preponderance of micropores over macropores.

2) Conventional tillage: This involves the manipulation of the soil to achieve a desirable tilth before planting, achieved either through mechanized operations or through manual operations. Shallow ploughing pulverizes the soil surface and causes the loosened layer to dry faster and completely, thereby helping to conserve moisture over a long period of time [7]. This phenomenon is common especially in sandy soils, which conduct water rapidly at high water content and slowly at low water content [16]. Effect of tillage type on soil moisture is dependent not only on soil but also on climate and crop grown. 
Mulch is defined in a wider sense in this paper to include all forms of protective coverage placed on or beneath the soils, with the aim of minimizing losses of soil moisture to evaporation and deep percolation as well as improving the soil hydrophysical condition. Surface mulch improves soil water conservation primarily by reducing the volume of runoff (the extent of which generally relates to its quantity) and by decreasing losses due to soil evaporation [17]. Its positive role of conferring on the soil aggregates the ability to withstand raindrops impact minimizes soil crusting and this encourages infiltration of the trapped runoff. Mulch could also improve the soil water-stable aggregates, total porosity and bulk density, thereby contributing positively to soil moisture retention [18]. Many different watertight or water-retardant materials could be used as surface mulch. Examples include straw or stubble, wood bark, cotton burs, sawdust, gravels, loose soil materials, latex oil, paper asphalt, plastic films, metal foils, etc. Surface mulch with crop residues has the advantage of providing protective cover at a time when crop cover is not practical [15]. The Soil Conservation Society (SCS) and the CTIC encourage crop-residue management which involves leaving the previous crops' residue on the soil surface in any tillage-planting system [12]. Plastic and oil mulches can be used to collect runoff in depressions in arid areas, and this is a form of runoff farming.

Though inconsistencies characterize results of tillage trials, conservation tillage seems more beneficial than conventional tillage in the long run on greater proportion of climatic regions and arable soils. Minimum tillage which provides standing mulch may be combined with mulch while maximizing the density of crops grown and the use of local materials as mulch. Manuring with organic residues or compost has also been shown to be very effective in conserving soil moisture [19,20]. In most cases, their positive effect on soil moisture storage is as a result of significant improvements in soil structure (porosity) and bulk density.

\subsubsection{Mechanical Conservation Works or Structures}

Generally, these consist of various types of earth or stone works built on or close to the contour, which aim to either reduce the length of a slope or the angle of the slope itself. Sand- and rock-filled dams used to raise the head of flowing water for irrigation also come under this category. There are a large number of mechanical works, and the main factor in deciding which to select must be to define the objective [21]. From agronomic standpoint, the ones with the potentials of enhancing water infiltration into the soil by influencing runoff especially on sloping lands include:

1) Terracing: This involves converting a steep slope into a series of steps with horizontal or nearly horizontal ledges and vertical walls of stone, brick, or timber between ledges. Terraces are made at right angles to the steepest slope and consist of an excavated channel on the uphill side, with the soil from this channel forming a bank on the downhill side [2]. Different types of terraces exist, depending on method of construction and the objective. Some are earth embankments constructed across a slope for conducting water from above at regulated flow to prevent accelerated erosion and to conserve water [14]. Most popular ones include bench, level, retention, graded channel, Nichols, broad-based and narrow-based terraces, as well as diversion terraces with mangum.

2) Contouring: Contour cultivation and contour banks are two important contouring practices. Contour cultivation, as the name implies, consists of cultivating the land on or close to the contour, and at right angles to surface water flow. Each furrow acts as a detention storage or small dam, slowing down the movement of runoff over the soil, thus giving the water time to infiltrate into the soil $[2,8]$. When they are simple structures and are constructed on the contour, they are generally termed "stop-wash lines”. Contour banks, otherwise known as bunds, are small banks built along the contour to catch and retain all runoff water and allow it to slowly infiltrate into the soil. In paddy fields, they serve as means of ensuring even distribution of ponded water and, hence, as indicators of the extent of levelling achieved in the field. They are usually 20-50 cm high [8], 150-200 cm wide, and form buffer strips at 10-20 m intervals across the slope [2].

Sometimes, banks are graded and waterways created with a spur at a disposal site. Graded banks with waterways, as they are called, involve constructions of waterways either along natural depressions or along some other suitable selected lines and grading them to a more or less regular shape. Grasses or trees are then planted on the waterway which is not cultivated again once the vegetation is established, but left as a permanent safe disposal area for excess water. A peculiar feature of this technique is the practice of contour cultivation later between banks constructed across the field with a very slight grade or fall towards the waterways. The whole arrangement is such that the contour cultivation and banks allow maximum absorption of water. Excess water resulting from heavy or high intensity rains would flow along the bank at non-erosive velocity until it reaches the end, from where if could then run slowly down the waterways and be safely disposed.

\subsection{Physicochemical Measures of Soil Moisture Conservation}

These measures are used in tackling the major problem of evaporation. They have also been found very useful in the reduction of deep percolation (in agricultural fields) and 
in the control of seepage (in reservoirs, canals, ditches). These are two other main avenues of moisture losses that must not be neglected especially in the humid and the sub-humid regions. A solely chemical approach to soil moisture conservation is the use of soil conditioners. They are oil or rubber-based emulsions of polyfunctional polymers that are capable of forming chemical bonds with soil clay minerals, leading to formation of aggregates [2].

\subsubsection{Reduction of Evaporation from Water Surfaces} Barriers that prevent vaporization could be used to cover the surface of water body (such as reservoirs and canals). These barriers could be physical solid objects or liquid chemicals. Commonly used solid objects include butyl rubber, plastics, blocks, rafts or beads, loose granular materials; all of which are membranes that can float on water. Liquid chemicals used physically in this technique are mainly monomolecular films made of fatty alcohols such as hexadecanol and waxes. Such films normally spread out to form a protective ceiling layer across the water surface. In all cases, the aim is to reduce surface area and/or protect the surface of free-water in contact with the atmosphere [22]. Recently, Segal and Burstein [23] proposed the use of parasol-type float, which can cover up to $80 \%$ of water surface at its maximum density.

\subsubsection{Control of Seepage}

The main cause of seepage in reservoirs is the flocculation of clays (into larger aggregates) by calcium ions, leaving cracks in between which result in leakages. Seepage could therefore be controlled by compacting the soil or by water-proofing the walls or bottom of the reservoir. Polythene or polypropylene films are also used to cover the walls of reservoirs that do not contain any works and are not more than $3 \mathrm{~m}$ deep. Deeper and rocky reservoirs require thicker and tougher films of vinyl or reinforced polypropylene materials. In both cases, the materials should be covered with soil or gravels to act as a protective material. Application of sodium salts such as $\mathrm{Na}_{2} \mathrm{CO}_{3}$ could reverse clay flocculation, i.e., deflocculate the clays and cause them to swell and plug the cracks. Other means of tackling the problem include [22]: 1) placing concrete or plastic linings and fiberglass-reinforced asphalt in irrigation canals and ditches; 2) mixing some swelling clays such as bentonite with surface soils to swell and seal soil pores to reduce infiltration; and 3) applying chemicals that can swell the soil particles and make the soil hydrophobic, thereby reducing infiltration capacity. Apart from asphalt, another chemical that could be used to treat the soil is butyl alcohol or butyl rubber.

\subsubsection{Reduction of Deep Percolation Losses}

This is usually not a problem in semi-arid and arid regions of the world, but in the humid regions where irrigated crop production is practised. Such losses are more problematic in coarse-textured soils that normally have low water holding capacity. The commonest way of reducing such losses is by placing of drainage barriers horizontally at about $60 \mathrm{~cm}$ below the soil surface. Plastic sheets, compost manures, or asphalts could be used. Installation of these barriers is usually achieved by either removing the topsoil, hand placing the barrier and refilling the soil or by using machines built for this purpose in the case of asphalt. The asphalt hardens immediately into 2-3 mm waterproof barrier. Another way of reducing deep percolation is by using chemicals that absorb large amount of water when incorporated into the soil. A typical example of such chemicals is a copolymer of starch and acrylonitile (known as super slurper), which absorbs up to 1400 times its weight of water.

\subsection{Economic Approach to Conservation of Water}

The use of trickle or drip irrigation in supplying water to growing crops could be viewed as an economic approach in the use and management of water in crop production. In this system developed by the Israelis, water is delivered directly to the crop through a system of plastic tubes placed under the soil. Only small amount of water are remitted at a time. The rate at the time of water application is adjusted so that evaporation losses are minimized and no runoff or deep percolation losses occur. In the more advanced types of drip irrigation, the water supply could be adjusted to replace water used by the plants or evapotranspiration.

\section{Appraisal of the Major Techniques of Conserving Soil Moisture}

Although all techniques so far discussed are useful in one way or the other for conserving soil water, they have their drawbacks. Sanders [8] noted that these limitations usually increase with the slope. Among other considerations, all soil water conservation and management techniques appear to have socio-economic constraint as a common factor militating against their adoption by especially resource-poor smallholder farmers [24]. The specific prospects (pros) and constraints (cons) of the techniques are discussed below.

\subsection{Biological Measures}

Pros: They improve water use efficiency and are very effective in weed control. They are the most satisfactory methods of building up the organic matter content and the associated structure and infiltrating capacity of soils. Hence, their benefits include dramatic reduction in wind and water erosion. Their benefits also include improve- 
ments in the productivity of eroded soils [2,12]. When legumes are used, the nitrogen status of the soil is improved for the cereal crop [21].

Cons: The effectiveness of these measures depends on the proper choice of the protective species, as regards ease of establishment, vigour of growth, depth of rooting, rapidity of establishment of surface cover, etc. [2]. Unless relay planting is practised, harvest of the first crop would leave the soil bare. The land area cover should be about $90 \%$ if the desired aim is to be achieved, but this is not easy to establish and maintain. Removal of phreatophytes usually goes with loss of wildlife habit [13].

\subsection{Physical or Mechanical Measures}

\subsubsection{Tillage, Mulch and Manuring Practices}

Agriculture and Rural Development [25] noted that there exist divergent views on the soil moisture conservation benefits of different tillage practices. These inconsistencies may be due to complexity of the changes in soil physicochemical properties caused by tillage, and the dependency of tillage effects on soil, crop and environmental conditions. The implication is that even when specific soil property changes on soil moisture are understood, the tillage required to achieve those changes may not be possible or known. In any case, evidence from the literature shows that both conservation and conventional tillage practices have their pros and cons.

\section{1) Conservation Tillage}

Pros: A very important advantage of conservation tillage is that the principles are equally effective in any conditions [21]. It is also effective in the control of wind erosion in large-scale mechanized cereal production and so precludes the need for terraces or other permanent structures [21]. The reviews of the effects of tillage systems on soil properties by Aina [2], Opara-Nadi [15] and Babalola and Opara-Nadi [26] reveal that the beneficial effects of no-till in soil and water conservation are more pronounced in the humid and sub-humid regions than in the semi-arid and arid regions where soils characterized by weak structure, low porosity and low infiltration rates are commonly found. The no-till results in savings in machinery investment and in the time required for seedbed preparation [2,15]. Other benefits of the system identified by these authors include prevention of erosion, enhancement of organic matter content, reduction of evapotranspiration, suppression of weed growth, improvement of water and nutrient use efficiency, maintenance of favourable soil temperature, and encouragement of biological activity. Additional benefits of no-till include improvement of soil physical characteristics, prevention of soil salinity, and promotion of crop growth [12].
Cons: It is less applicable to low-input level of crop production or subsistence agriculture in especially areas with low rainfall [21]. Other constraints to conservation tillage in semi-arid regions include the value of crop residues as livestock feed, difficulty of planting through surface mulches by ox-drawn planters, and the incompatibility of dense plant covers with the well-tested strategy of using low plant populations to suit low moisture availability [21]. Furthermore, no-till has proven less effective on especially hydromorphic and compacted soils with poor internal drainage [2]. The heavy dependence on herbicides and pesticides could be cost-prohibitive [2] and might lead to serious water pollution [13].

\section{2) Conventional Tillage}

Pros: Air permeability, soil water diffusivity and water distributions down the soil profile all could increase with intensity of tillage [27]. Ploughing operations such as ripping or subsoiling can be beneficial, either to increase soil porosity at least for a short time especially in compact soils, or to break a pan which is restricting surface detention and storage, infiltration and permeability, and root development [2,21]. By enhancing infiltration, ploughing can help to minimize runoff and consequently erosion. Puddling, ploughing the soil under water-saturated condition especially in paddy fields, enhances water retention mainly by reducing deep percolation. It is, perhaps, the only known form of conventional tillage that always enhances soil water retention irrespective of location.

Cons: One of the major limitations of conventional tillage is the lack of sustainability in soils of low aggregate stability [2]. This author noted also that if the ploughing operation is not carried out at the appropriate soil moisture conditions, structural breakdown and smearing may occur and the system may not be effective. Intensive soil cultivation may increase the bulk density and unfavourably alter the pore size distribution [28]. Furthermore, the effects of conventional tillage on soil moisture could be crop-dependent. With puddling, there seems to be an intensity threshold beyond which there occurs a reduction in yield of the crops that succeed rice [29]. And this may be linked with the soil structure-destroying attribute of puddling. Other limitations to the widespread practice of conventional tillage include laboriousness (especially when hand-operated tools and implements such as hoes are used) and the inevitable disruption of the activity of some beneficial living components of the soil.

\section{3) Mulch}

Pros: Mulch, by decreasing flow velocity, improves infiltration and hence controls erosion [2,21,30]. FAO [17] noted that both soil sorptivity and transmissivity increase with increasing mulch level and that crop-residue mulch 
helps to maintain the quality of water running off the agricultural land. All forms of mulch regulate the soil temperature [17,30,31]. The gravel mulch reduces both wind and water erosion and, if light-coloured, cools the soil. Mulch provides other special effects such as avoiding formation of hardpan, promoting soil aggregate formation, reducing soils' scours and wind erosion, increasing soil organic matter content, promoting soil microbial activities, and decomposing to release plant nutrients [12,17]. Suppression of weeds by mulch prevents transpiration losses from those weeds. Increase in soil temperature associated with mulch in cold regions could hasten early plant germination, seedling growth and development. In the semi-arid tropics, mulch is also known to trap nutrient-rich, wind-borne dust and improve root growth [30]. Use of soil as mulch material (soil mulch) is characterized by low input and ease of operation [12]. All forms of mulch improve the quality of some fruits (e.g. tomato, eggplants, and pepper) by preventing contact with soil. Additional benefits of mulch include stabilization of loose soils, stoppage of desert encroachment, and reduction of build-up of soil salinity.

Cons: FAO [21] outlined the following possible limitations of mulch: 1) mismatch between the amount of crop residue required and the amount available from low-level production; 2) problems of pest, disease, or nitrogen lock-up; 3) lack of implements which can plant or drill through the mulch; and 4) liability of organic mulch to rapid oxidation by high temperatures. FAO [17] noted that transporting mulch for large-scale cropping could be economically prohibitive. Others limitations of mulch include [16]: 1) use of organic mulch as livestock feed and as building materials during the long dry season; 2) high cost and general unavailability of contoured plastic mulch in most of West Africa; 3) ineffectuality at the end of the growing season since conserved water rapidly drains through the soil profile during the dry season; 4) tendency to be potentially more beneficial in the semi-arid and arid regions than in the humid and sub-humid regions.

\subsubsection{Mechanical Conservation}

\section{1) Terracing}

Pros: Terracing is a very effective way of controlling runoff and water erosion. Bench terracing, the best type, is particularly useful in this regard on slopes of between 12 and $35 \%$ but sometimes on steeper slopes say $40 \%[2,8]$. Bench terracing permits the cultivation of lands that are too steep for crop production, which otherwise would not be possible [8]. The level bench terrace is ideal for areas with low rainfall and for practicing irrigation in areas with rough terrain $[10,21]$. Similarly, graded channel terraces are suitable under situations of heavy rain on shallow soils with limited storage capacity [21].
Cons: Terraces, especially the bench type, are prohibitively expensive to construct because of the large volume of soil which has to be moved, relative to returns from subsistence farming $[2,8,10]$. Careful maintenance is subsequently required, and this is also expensive [2,8], and may even be impossible because of labour shortages $[3,21]$. Moreover, only few terraces are likely to have widespread application in semi-arid areas [21]. A particular type (channel terrace) actually leads water away from the farm and so is not suitable for dry areas, just as level bench terraces are not suitable on heavy soils due to very low infiltration rates [8]. Consideration of soil factors (such as infiltration rate, permeability, erodibility, and depth), slope, bund height, and proposed land use during the designing stage prior to construction of terraces contributes to reluctance in adoption of the practice.

\section{2) Contouring}

Pros: Contour cultivation is the simplest form of mechanical conservation work. Traditional systems concentrate relatively nutrient-rich surface soil around the roots of cultivated plants [17]. It is a cheap way of water erosion control that is immediately effective when the land is newly cultivated [8], and could reduce soil loss to approximately half of the potential rate with cultivation up and down the slope [21]. Contour bunds also permit cultivation to be carried out on the contour. They have the dual purpose of conserving both soil and water by reducing runoff and erosion [2,8,21]. Where earthen bunds are used, initial construction cost are usually minimal. Contour bunds are useful for rangeland rehabilitation, especially where trees are to be incorporated, since they could be planted on a hole on the lowest end of the impounded area [10].

Cons: Furrows in contour cultivation often break down quickly and sometimes are not effective for a very long period [8]. Its effectiveness in soil and water conservation depends not only on the design of the system, but also on soil, climate, slope aspect and land use [2]. Thus, this author noted that it is comparatively less effective on compact or slowly permeable soils which become saturated quickly. Contour bunds could only be used effectively where infiltration rate of the soil is high and the rainfall intensities low, because if one bank overtops and breaks, the whole system could fall [8]. They are suitable only for gentle slopes, otherwise there would be too great a difference between the depth of water at the lower end and at the upper end, unless the bunding intervals are very small [10]. Although this kind of problem could be avoided with proper soil levelling as is being done under the sawah system of rice production in the inland valleys in some parts of West Africa, the task could be quite labourious. In the case of earthen bunds, reconstruction at the start of every growing season adds to the production 
cost. Bunds also occupy spaces that otherwise would have crops grown on them.

\subsection{Physicochemical Measures}

\subsubsection{Reduction of Evaporation from Water Surfaces}

Pros: They require little construction, hence cost is minimized. In the semi-arid and arid regions, application of fatty alcohol emulsions on the surface of dam reservoirs could reduce evaporation by up to $48 \%$ [32]. Since it involves reduction in evaporation of water stored in earthen dams, salt concentration that usually accompanies evaporation is reduced. By cutting off light from the water surface, floating evaporation control devices reduce the growth of algae and submerged aquatic weeds.

Cons: Sand storage tanks are difficult to construct and require a lot of patience, hence the perceived sluggishness in wide acceptance of the technology for building them. Protection of free-water surfaces to reduce evaporation is uneconomical except in special situations [22]. Such devices are very difficult to apply over large surfaces because of the adverse effects of wind action, heavy rainstorms, and floods. When monomolecular films and fatty alcohol emulsions are used, they hardly survive biological deterioration, and so must be applied regularly to compensate for this attack [22,32]. Use of liquid chemicals normally leads to pollution of the environment. Although this is not a problem with the parasol-type float, its installation is characterized by labour intensiveness and practical difficulties [23].

As for soil conditioners, their application has been found to improve the infiltration rate and the size and stability of pore spaces [2,22], hence they can reduce runoff and increase the water holding capacity of soils. Aina [2] reported that the effective temporary erosion control achieved when soil conditioners cover the whole soil surface could be comparable with the $70 \%$ coverage required for erosion control using mulch and plant covers. As the period of effectiveness of commercially available soil conditioners decreases, cost of application increases. Some bitumen treatments, for example, are only effective in runoff control only for a few storms. Moreover, whereas high infiltration rates may be achieved with poly-acrylamide conditioners regardless of the size or distribution of aggregates, most emulsions such as asphalt and latex emulsions demand that the aggregates must be at least $1 \mathrm{~mm}$ in size and ideally greater than $5 \mathrm{~mm}$ before they could be effective.

\subsubsection{Control of Seepage}

Pros: Control of seepage through the walls of reservoirs strengthens those walls against collapse, especially by plugging cracks and preventing preferential wetting of the surfaces in the dry season. Water taken from reservoirs seeded with bentonite or any other swelling clay (for the purpose of sealing the pores) would definitely add to the fertility of the soil to which it is applied, due to content of some dissolved nutrients from the clay.

Cons: When compaction of the soil is to be used, achieving the effective extent of compaction is an arduous task. Even when reasonable compaction of the soil is achieved, it has to be uniform otherwise its effectiveness would remain questionable. Use of sodium salts to deflocculate clay for plugging cracks in the walls of reservoirs is practicable only in soils that are at least $30 \mathrm{~cm}$ deep, with a minimum of $15 \%$ clay content and a capacity to exchange calcium for sodium. All the methods of controlling seepage are costly to install and maintain.

\subsubsection{Reduction of Deep Percolation Losses}

Pros: It is suitable for coarse-textured soils with low water holding capacity. The drainage barriers prevent nutrients from being lost through deep percolation. Contamination of groundwater by agrochemicals dissolved in soil water is avoided.

Cons: Installation of drainage barriers by the method of topsoil removal is very tedious. The method is also not suitable on lands where no-till practice is proposed. The fact that the super slurper (used for moisture absorption) may be biodegradable is frustrating. Above all, the use of all forms of drainage barriers is discouraged by cost.

\subsection{Economic Approach: The Use of Trickle Irrigation}

Pros: This is very economical in areas where water is scarce or expensive. It is suitable in areas where wind velocity is too high for sprinkler irrigation or where water quality is poor with high erosion and surface contamination risk. The technique does not require land leveling or specially trained labour. It is suitable on soils that are either too porous or too impervious for flood or furrow irrigation. It is a very efficient means of fertigation.

Cons: There could sometimes be clogging of air meters by precipitates of limestone- or ion-containing water, fine sand, silt, suspended clay, and algae. Growing of more than one crop with differential rooting depths is not usually possible. It impedes cultivation and free movement of machineries, especially when placed at shallow depths.

\section{Conclusions}

The paper reveals that a wide range of techniques have the potential to conserve soil moisture and free-water surface. These have been broadly grouped into biological, physical, chemical and economic soil moisture conservation techniques. Although the basic principles in all the practices are potentially of universal applicability, con- 
servation practices developed in one region may need field testing and verification before adoption elsewhere. Moreover, all the techniques have their limitations and drawbacks, just as the effectiveness of each depends on a number of factors. The choice of appropriate techniques depends on soil, topography, climate, scale of production, and technological and socio-economic status. Prospective techniques should be evaluated in the light of their potential benefits vis-à-vis the adoption drawbacks, while considering socio-cultural acceptability and environmental safety. In most but not all scenarios, carefully selected agronomic practices could serve as a sustainable substitute to the almost abandoned practice of long fallows which are very effective in soil and water management, and may be more useful than engineering structures. However, since there are no universally effective practices, combination of more than one technique is considered to be a promising approach to producing efficacious results in any location. Future research in such an integrated approach to soil water management is expected to focus on the compatibility of selected possible techniques on watershed basis.

\section{Acknowledgements}

The first author (SEO) thanks one of his highly revered teachers and mentors, the late Professor JSC Mbagwu.

\section{References}

[1] FAO, "Biomass Production in Dry Tropical Zones: How to Increase Water Productivity," FAO Land \& Water Bulletin, Vol. 1, FAO, Rome, 1995a.

[2] P. O. Aina, "Rainfall Runoff Management Techniques for Erosion Control and Soil Moisture Conservation,” Soil Tillage in Africa: Needs and Challenges. FAO Soils Bulletin, Vol. 69, FAO, Rome, 1993.

[3] I. E. Ahaneku, "Conservation of Soil and Water Resources for Combating Food Crises in Nigeria," Scientific Research \& Essays, Vol. 5, No. 6, 2010, pp. 507-513.

[4] I. A. Shiklomanov, "World Water Resources and Their Use,” A Joint Publication of State Hydrological Institute and UNESCO's International Hydrological Programme, 1999.

http://webworld.unesco.org/water/ihp/db/shiklomanov/in dex.shtml

[5] R. Coopey, H. Fahlbusch, N. Hatcho and L. Jansky, “A History of Water Issues: Lessons to Learn,” United Nations University, New York, 2005, p. 278.

[6] E. Kato, C. Ringler, M. Yesuf and E. Bryan, "Soil and Water Conservation Technologies: A Buffer against Production Risk in the Face of Climate Change? Insights from the Nile Basin in Ethiopia,” IFPRI Discussion Paper 00871, 2009. http://www.ifpri.org/publication/soil-and-water-conservat ion-technologies-buffer-against-production-risk-face-clim ate-cha

[7] D. Hillel, "Introduction to Soil Physics," Academic Press, New York, 1982.

[8] D. W. Sanders, "Soil Conservation Practices," A paper presented at College on Soil Physics, the Abdus Salam International Centre for Theoretical Physics (I.C.T.P.), Trieste, Italy, April 15-May 3, 1985.

[9] M. E. Obi and P. C. Nnabude, “Testing Tillage Variants on a Sandy Loam Soil (Dystric Nitosol) in Nigeria as Regards Soil Conservation, Yield, and Water Utilization,” Beitrage zur Tropischen Landwirtschaft und Veterinarmedizin, Vol. 28, No. 3, 1990, pp. 291-302.

[10] P. Smith, "Soil and Water Conservation," In: J. R. J. Rowland, Ed., Dryland Farming in Africa, Macmillan Education Ltd., London, 1993, pp. 142-171.

[11] T. Snell, “Agroforestry Practices,” A publication of the Kerr Centre, 2000.

http://www.kerrcenter.com/publications/Agroforestry.htm

[12] L. Yinli and W. Zongming, "The Benefit and Prospect of No-Till and Cropland Mulch on Water Conservation of Loess Plateau in China," A Paper Presented at the 12th Conference of International Soil Conservation Organization, Beijing China, May 25-31, 2002.

[13] G. O. Schwab, D. D. Fangmeier, W. I. Elliot and R. K. Frevert, "Soil and Water Conservation Engineering (4th ed.)”, John Wiley and Sons, Inc., New York, 1993.

[14] SSSA, "Glossary of Soil Science Terms”, ASA, CSSA, SSSA, ASF, Madison WI, USA, 2001.

[15] O. A. Opara-Nadi, "Conservation tillage for increased crop production,” In: FAO, Soil Tillage in Africa: Needs and Challenges, FAO Soils Bulletin, 69, 1993. FAO, Rome.

[16] W. A. Payne, "Shallow Tillage with a Traditional West African Hoe to Conserve Soil Water", Soil Science Society of America Journal, Vol. 63, 1999, pp. 972-976. doi:10.2136/sssaj1999.634972x

[17] FAO, “Tillage Systems in the Tropics”, FAO Soils Bulletin, 71, 1995. FAO, Rome.

[18] J. S. C. Mbagwu, "Mulching an Ultisol in southern Nigeria: Effects on Physical Properties and Maize and Cowpea Yields", Journal of the Science of Food and Agriculture, Vol. 57, 1991, pp. 517-526. doi:10.1002/jsfa.2740570405

[19] P. C. Nnabude and J. S. C. Mbagwu, "Soil Water Relations of a Nigerian Typic Haplustult Amended with Fresh and Burnt Rice-Mill Wastes," Soil and Tillage Research, Vol. 50, 1999, pp. 207-214. doi:10.1016/S0167-1987(98)00193-7

[20] M. J. Curtis and V. P. Claassen, "Compost Incorporation Increases Plant Available Water in a Drastically Disturbed Serpentine Soil,” Soil Science, Vol. 170, No. 12, 2005, pp. 939-953. doi:10.1097/01.ss.0000187352.16740.8e

[21] FAO, "Soil and Water Conservation in Semi-Arid Areas," FAO Soils Bulletin, Vol. 57, FAO, Rome, 1987. 
[22] G. O. Schwab, D. D. Fangmeier and W. I. Elliot, "Soil and Water Management Systems,” $4^{\text {th }}$ Edition, John Wiley and Sons, Inc., New York, 1996.

[23] L. Segal and L. Burstein, "Retardation of Water Evaporation by a Protective Float," Water Resources Management, Vol. 24, No. 1, 2010, pp. 129-137. doi:10.1007/s11269-009-9440-3

[24] R. Foti, C. Gadzirayi and E. Mutandwaf, "The Adoption of Selected Soil Fertility and Water Management Technologies in Semi-Arid Zimbabwe: An Application of the Tobit Model," Journal of Sustainable Development in Africa, Vol. 10, No. 3, 2008, pp. 315-330.

[25] Agriculture and Rural Development, “Tillage Effects on Soil Moisture,” A publication of Alberta Government, 2004.

http://www1.agric.gov.ab.ca/\$department/deptdocs.nsf/all /eng8174

[26] O. Babalola and O. A. Opara-Nadi, "Tillage Systems and Soil Properties in West Africa”, Soil and Tillage Research, Vol. 27, 1993, pp. 149-174. doi:10.1016/0167-1987(93)90066-X

[27] A. P. Hamblin and D. Tennant, "The Influence of Tillage on Soil Water Behaviour,” Soil Science, Vol. 132, No. 3, 1981, pp. 233-239. doi:10.1097/00010694-198109000-00007
[28] M. E. Obi, “The Effect of Conventional and No-Tillage Practices on Physical Properties of an Ultisol and on Yields of Crops in Southern Nigeria”, Beitrage zur Tropischen Landwirtschaft und Veterinarmedizin, Vol. 27, No. 3, 1989, pp. 287-295.

[29] V. K. Arora, P. R. Gajri and H. S. Uppal "Puddling, Irrigation, and Transplanting-Time Effects on Productivity of Rice-Wheat System on a Sandy Loam Soil of Punjab, India,” Soil and Tillage Research, Vol. 85, No. 1-2, 2006, pp. 212-220. doi:10.1016/j.still.2005.01.015

[30] Y. Tilander and M. Bonzi, "Water and Nutrient Conservation through the Use of Agroforestry Mulches, and Sorghum Yield Response”, Plant and Soil, Vol. 197, 1997, pp. 219- 232. doi:10.1023/A:1004263930096

[31] S. O. Agele, G. O. Iremiren and S. O. Ojeniyi, "Effects of Tillage and Mulching on the Growth, Development and Yield of Late-Season Tomato (Lycopersicon esculentum L.) in the Humid South of Nigeria,” Journal of Agricultural Science, Vol. 134, No. 1, 2000, pp. 55-59. doi:10.1017/S0021859699007273

[32] M. I. Al-Saud, "Reduction of Evaporation from Water Surfaces-Preliminary Assessment for Riyadh Region, Kingdom of Saudi Arabia,” Research Journal of Soil and Water Management, Vol. 1, No. 1, 2010, pp. 5-9. 